\title{
Caenorhabditis elegans: A Model System for Anti-Cancer Drug Discovery and Therapeutic Target Identification
}

\author{
Robert A. Kobet ${ }^{1}$, Xiaoping Pan ${ }^{2}$, Baohong Zhang' ${ }^{2}$, Stephen C. Pak ${ }^{3}$, Adam S. Asch ${ }^{1,4,5}$ and Myon-Hee Lee ${ }^{1,4, *}$ \\ ${ }^{1}$ Department of Medicine, Department of Oncology, Division of Hematology/Oncology, Brody School of Medicine, East Carolina \\ University, Greenville, NC 27834, ${ }^{2}$ Department of Biology, East Carolina University, Greenville, NC 27858, ${ }^{3}$ Department of Pediatrics, \\ University of Pittsburgh School of Medicine, Children's Hospital of Pittsburgh of UPMC, 4401 Penn Avenue, Pittsburgh, PA 15224, \\ ${ }^{4}$ Lineberger Comprehensive Cancer Center, University of North Carolina-Chapel Hill, Chapel Hill, NC 27599, ${ }^{5}$ Current address: \\ Department of Medicine, Division of Hematology/Oncology, University of Oklahoma Health Science Center, Oklahoma City, OK \\ 73104, USA
}

\begin{abstract}
The nematode Caenorhabditis elegans (C. elegans) offers a unique opportunity for biological and basic medical researches due to its genetic tractability and well-defined developmental lineage. It also provides an exceptional model for genetic, molecular, and cellular analysis of human disease-related genes. Recently, C. elegans has been used as an ideal model for the identification and functional analysis of drugs (or small-molecules) in vivo. In this review, we describe conserved oncogenic signaling pathways (Wnt, Notch, and Ras) and their potential roles in the development of cancer stem cells. During C. elegans germline development, these signaling pathways regulate multiple cellular processes such as germline stem cell niche specification, germline stem cell maintenance, and germ cell fate specification. Therefore, the aberrant regulations of these signaling pathways can cause either loss of germline stem cells or overproliferation of a specific cell type, resulting in sterility. This sterility phenotype allows us to identify drugs that can modulate the oncogenic signaling pathways directly or indirectly through a high-throughput screening. Current in vivo or in vitro screening methods are largely focused on the specific core signaling components. However, this phenotype-based screening will identify drugs that possibly target upstream or downstream of core signaling pathways as well as exclude toxic effects. Although phenotype-based drug screening is ideal, the identification of drug targets is a major challenge. We here introduce a new technique, called Drug Affinity Responsive Target Stability (DARTS). This innovative method is able to identify the target of the identified drug. Importantly, signaling pathways and their regulators in C. elegans are highly conserved in most vertebrates, including humans. Therefore, $C$. elegans will provide a great opportunity to identify therapeutic drugs and their targets, as well as to understand mechanisms underlying the formation of cancer.
\end{abstract}

Key Words: Caenorhabditis elegans, Wnt, Notch, Ras, Cancer stem cells, Drug screening

\section{CAENORHABDITIS ELEGANS AS A MODEL SYSTEM}

The nematode Caenorhabditis elegans (C. elegans) is a multicellular organism that has become a popular model for biological and basic medical research. It has also been widely used as a model system to explore fundamental questions in multiple aspects of biology, including evolution, development, cell fate specification, stem cell regulation, tumorigenesis, and aging. The $C$. elegans has also been considered as an ideal model system for live animal high-throughput drug screening, as 1) their tissues are transparent at all developmental stages, 2) tissue-specific fluorescent transgenic markers to study physiological and cellular processes in vivo are well established, 3) a large number of mutant strains are available in Caenorhabditis Genetics Center (CGC) [http://www.cbs.umn. edu/research/resources/cgc], 4) whole genome sequencing has been completed, 5) they have a short lifespan (2 to 3 weeks) and a strong genetic power, and 6) the aspects of mammalian diseases can be successfully modeled in the $C$. elegans (O'Reilly et al., 2014).

The $C$. elegans life cycle includes embryogenesis $(\sim 12 \mathrm{~h})$, four larval stages (L1-L4; total of $\sim 3$ days) and adulthood $(\sim 10$

\section{Open Access http://dx.doi.org/10.4062/biomolther.2014.084}

This is an Open Access article distributed under the terms of the Creative Commons Attribution Non-Commercial License (http://creativecommons.org/licenses/by-nc/3.0/) which permits unrestricted non-commercial use, distribution, and reproduction in any medium, provided the original work is properly cited.
Received Jul 14, 2014 Revised Aug 14, 2014 Accepted Aug 18, 2014 Published online Sep 30, 2014

*Corresponding Author

E-mail: leemy@ecu.edu

Tel: +1-252-744-3134, Fax: +1-252-744-3418 


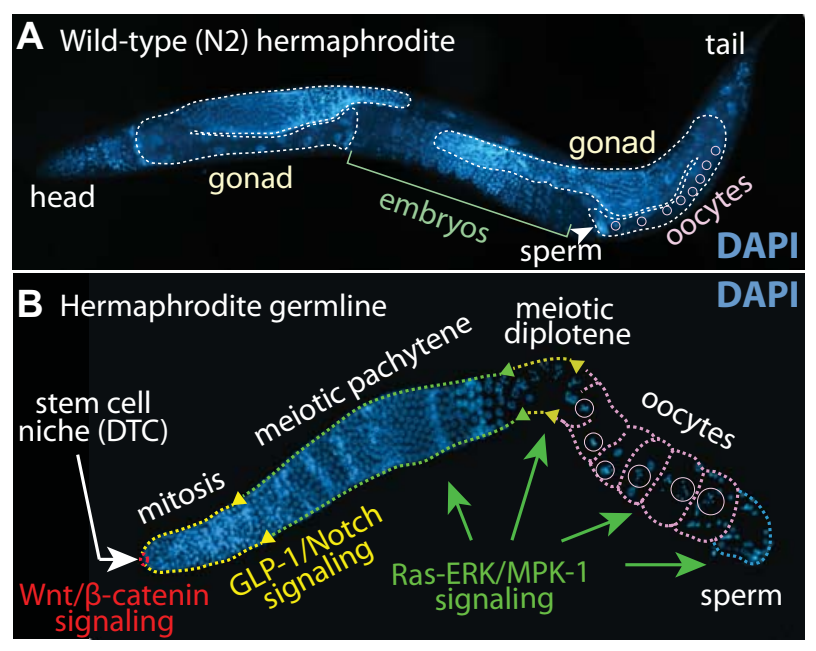

c

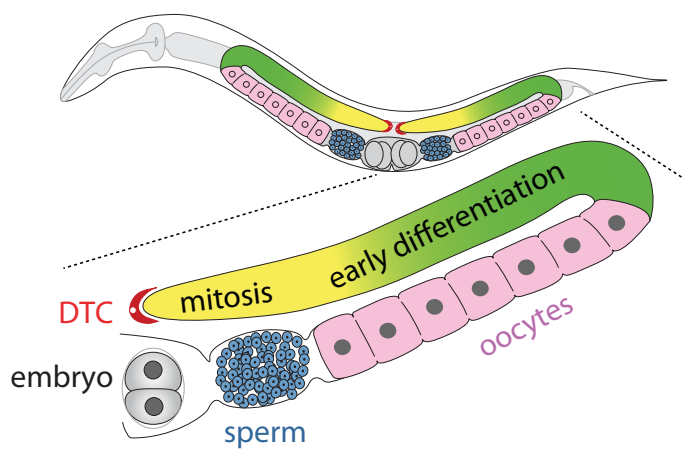

Fig. 1. C. elegans and conserved signaling pathways. (A) An adult wild-type (N2) hermaphrodite stained with DAPI (4',6-diamidino2-phenylindole). The hermaphrodite has two gonadal tubes. They produce both sperm and oocytes, and are therefore self-fertile (see embryos). (B) A dissected adult hermaphrodite germline stained with DAPI. In the distal end, somatic gonadal cell, called DTC (see dotted red circle), acts as a germline stem cell niche that is essential for germline stem cell maintenance. The DTC fate is specified at least in part by $\mathrm{Wnt} / \beta$-catenin signaling in early larval stage (L1). In the distal mitotic region (see dotted yellow lines), GLP-1/Notch signaling maintains germline stem cell self-renewal and promotes mitotic cell cycle of progenitor cells. Once mitotic cells enter meiotic cell cycle, Ras-ERK MAPK signaling promotes meiotic germ cell progression (see dotted green lines), pachytene exit (see dotted yellow lines), oocyte maturation (see dotted pink lines; circle, oocyte nuclei) and sperm (see dotted blue lines) fate specification. (C) Schematic of an adult C. elegans hermaphrodite gonad. Somatic DTC is located at the distal end. Cells at the distal end of the germline, including germline stem cells, divide mitotically (yellow). As cells move proximally, they enter meiosis (green) and differentiate into either sperm (blue) or oocytes (pink).

days) (Kimble and Crittenden, 2005). C. elegans exists as either hermaphrodites or males. Wild-type hermaphrodites can produce sperm during larval development (L3-L4) and then switch to oogenesis in adulthood (Fig. 1A, 1C). However, males make sperm continuously throughout their lifespan. In addition, the germline is organized in a simple linear fashion that progresses from germline stem cells at one end to maturing gametes at the other (Fig. 1B, 1C). C. elegans germline development is tightly regulated by conserved external signaling pathways, including Wnt, Notch and Ras, (Fig. 1B) as well as intrinsic regulators, including gene expression regula- tors and cell cycle regulators (Kimble and Crittenden, 2007). Aberrant control of these signaling pathways can cause the loss of the somatic distal tip cells (DTCs, which function as the germline stem cell niche) and germline stem cells as well as extra DTC formation, uncontrolled germline proliferation, and abnormal germ cell fate specification that are all associated with sterility and germline tumors. Therefore, these features of $C$. elegans germline make it a very suitable organism for the phenotype-based high-throughput screening of drugs that target oncogenic signaling pathways and the identification of therapeutic targets.

\section{ONCOGENIC PATHWAYS: WNT SIGNALING}

\section{Overview of Wnt signaling pathway}

The Wnt signaling pathway is critical for many aspects of animal development, including stem cell self-renewal, differentiation, cell fate specification, polarity, and cell migration (Katoh, 2008). There are three Wnt signaling pathways: canonical Wnt/ $\beta$-catenin pathway, non-canonical Wnt/planar cell polarity (PCP) pathway, and non-canonical Wnt/calcium pathway (James et al., 2008). All three Wnt signaling pathways are activated by the binding of Wnt ligand to Frizzled family receptor. In absence of its ligand, cytoplasmic $\beta$-catenin interacts with APC (polyposis coli) and Axin scaffold proteins, and then is phosphorylated by CKI $\alpha$ kinase and GSK3 $\beta$ (Glycogen Synthase Kinase $3 \beta$ ). The phosphorylated $\beta$-catenin is then ubiquitinated and degraded by the proteasome (Fig. 2A). Therefore, in the canonical pathway, CKI $\alpha$, GSK $3 \beta$, APC, and Axin act as negative regulators. Upon activation, the formation of APC/Axin/CKI $\alpha /$ GSK3 $\beta$ destruction complex is inhibited, which stabilizes $\beta$-catenin and leads to its localization in the nucleus (Fig. 2B). In the nucleus, $\beta$-catenin interacts with TCF family transcription factors to activate the expression of target genes such as FGF20, DKK1, WISP1, MYC, and Cyclin D1 (He et al., 1998; Pennica et al., 1998; Tetsu and McCormick, 1999; Chamorro et al., 2005) (Fig. 2B). Importantly, these target genes have been implicated in the development of multiple types of cancer, including colon, breast, ovarian, and thyroid.

\section{Wnt signaling and cancer stem cells}

Over the past several years, increasing evidence has been found to be in support of the theory of cancer stem cells (sometimes called tumor stem cells or tumor-initiating cells). Cancer cells are heterogeneous, containing abundant proliferative cells (non-cancer stem cells) and rare cancer stem cells. Furthermore, it has been proven that cancer stem cells are similar to normal stem cells in many aspects and exist in multiple cancers such as leukemia, breast cancer, and lung cancer (Visvader and Lindeman, 2012). Therefore, specific therapies targeted at cancer stem cells hold a tremendous promise to increase the efficiency and safety of cancer treatment.

The canonical $\mathrm{Wnt} / \beta$-catenin is critical for the regulation of embryonic stem cells, adult stem cells, and cancer stem cells (Nusse et al., 2008). In normal stem cells, the self-renewal and differentiation of stem cells are tightly regulated at least in part by $\mathrm{Wnt} / \beta$-catenin signaling. For example, R-spondin growth factors interact with Leucine-rich repeat-containing $\mathrm{G}$ protein-coupled receptors (Lgr) (Chen et al., 2013; Wang et al., 2013). These R-spondin/Lgr complexes and Wnt ligands 
A. Absence of Ligand

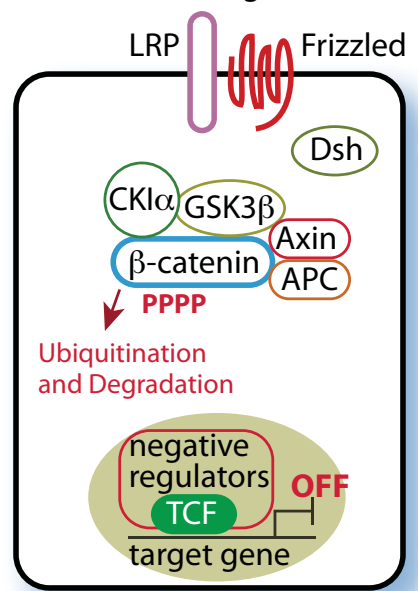

B. Presence of Ligand

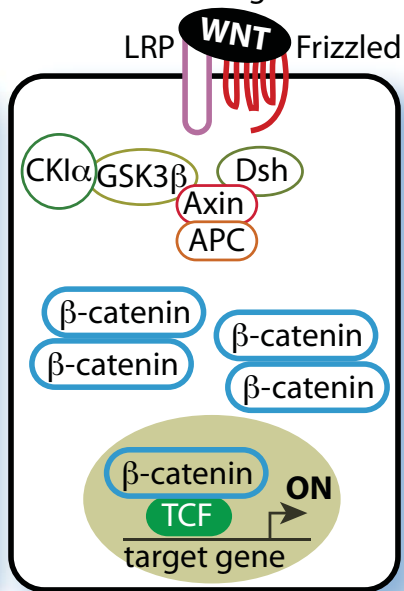

C C. elegans Wnt/ß-catenin signaling

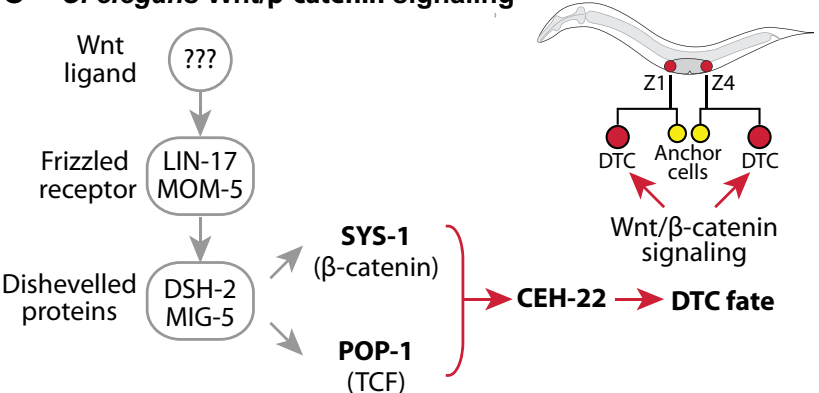

D. wild-type

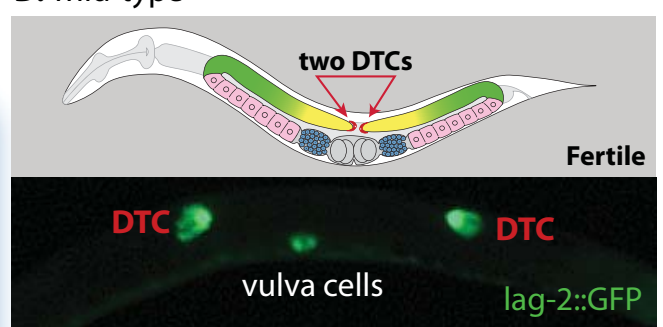

E. Loss of Wnt/ $\beta$-catenin signaling

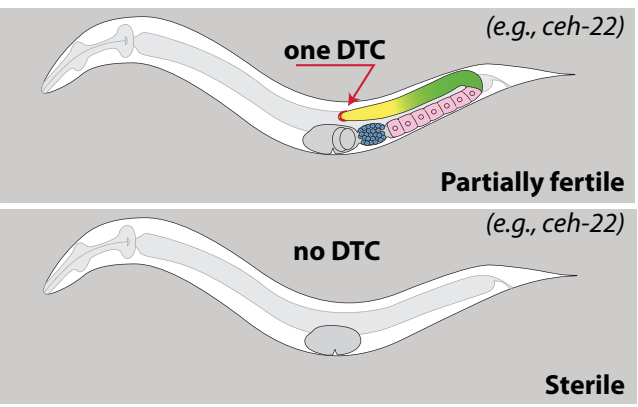

F. Activation of Wnt/ß-catenin signaling

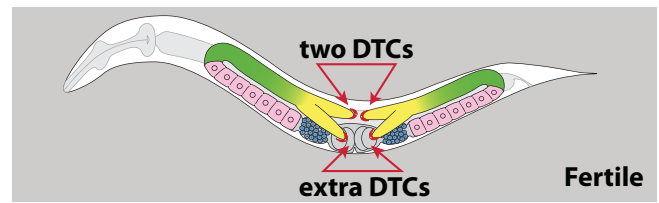

G. Drug screening for Wnt/ß-catenin signaling

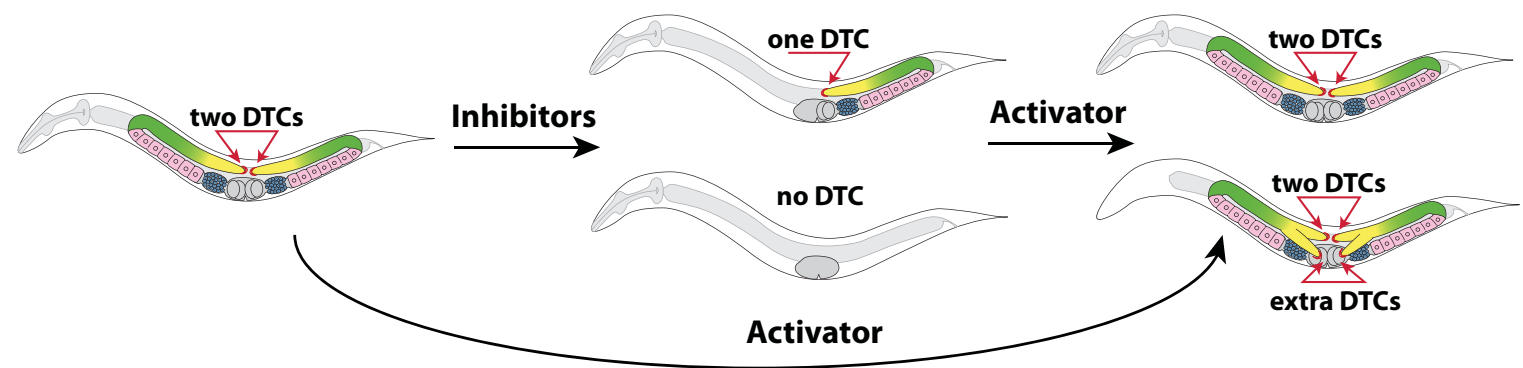

Fig. 2. Wnt/ $\beta$-catenin signaling pathways and a strategy for the phenotype-based drug identification using $C$. elegans mutants. (A) Without signaling (absence of ligand), negative regulators (CKI $\alpha$, GSK3 $\beta$, Axin, and APC) phosphorylate $\beta$-catenin, and then ubiquitinated and degraded by the proteasome. (B) With signaling (presence of ligand), stabilized $\beta$-catenin in cytoplasm is translocated into nucleus and activate the expression of target genes. (C) Genetic pathway for control DTC fate specification (see text for explanation). (D) Wild-type hermaphrodite has two DTCs. lag-2::GFP reporter is strongly expressed in DTCs (see green). (E) Loss of Wnt/ $\beta$-catenin signaling affects DTC fate specification. (F) Activation of Wnt/ $\beta$-catenin signaling contributes to extra DTC formation. (G) Strategy for the phenotype-based identification of drugs that either inhibit or activate $W n t / \beta$-catenin signaling using $C$. elegans mutants.

directly interact with Frizzled receptors on target cells to activate downstream signaling (Birchmeier, 2011). This signaling and downstream activation have been found to be important for the self-renewal and differentiation of stem cells and cancer stem cells (Reya and Clevers, 2005; Holland et al., 2013). Notably, Wnt/ $\beta$-catenin signaling is likely to control mammary gland stem cell maintenance at different stages of development (Wend et al., 2010; Holland et al., 2013). Mammary gland stem cells can give rise to ductal, basal/myoepithelial and alveolar components (Holland et al., 2013). Therefore, aberrant activation of $\mathrm{Wnt} / \beta$-catenin signaling contributes to the maintenance of cancer stem cells and results in mammary gland tumorigenesis. In addition, $W n t / \beta$-catenin signaling has been implicated in the regulation of stem cells and cancer stem cells in the nervous system, hematopoietic system, skin, and intestine (Holland et al., 2013). Therefore, the inhibition of $W n t / \beta$-catenin signaling might reduce the capacity of cancer stem cells, which could be of potential therapeutic benefit in treating multiple types of cancer.

\section{C. elegans canonical Wnt/ $\beta$-catenin signaling}

Conserved Wnt/ $\beta$-catenin signaling pathways and core components in C. elegans somatic gonads are summarized in Fig. 2C, and well described in (Eisenmann, 2005). This 
Table 1. Summary of oncogenic signaling pathways and mutant phenotypes

\begin{tabular}{|c|c|c|c|}
\hline Signaling pathway & Mutants or transgenic lines & Phenotypes & Reference \\
\hline \multirow[t]{6}{*}{ Wnt/ $\beta$-catenin signaling } & $p o p-1(q 645)$ & DTC loss (100\%) and sterile & (Siegfried and Kimble, 2002) \\
\hline & sys-1(q544) & DTC loss (100\%) and sterile & (Kidd et al., 2005) \\
\hline & $\operatorname{lin}-17(n 671)$ & DTC loss $(<10 \%)$ and partially sterile & (Phillips et al., 2007) \\
\hline & ceh-22(q632) & DTC loss $(\sim 40 \%)$ and partially sterile & (Lam et al., 2006) \\
\hline & $h s:: s y s-1$ & Extra DTCs and fertile & (Kidd et al., 2005) \\
\hline & hs::ceh-22 & Extra DTCs and fertile & (Lam et al., 2006) \\
\hline \multirow[t]{5}{*}{ GLP-1/Notch signaling } & $g l p-1(q 46)$ & No GSCs (“GIp” phenotype) & (Austin and Kimble, 1987) \\
\hline & glp-1(bn18)ts & Fertile at $20^{\circ} \mathrm{C}$ & (Nadarajan et al., 2009) \\
\hline & $g / p-1(q 224) t s$ & "Glp" phenotype at $25^{\circ} \mathrm{C}$ & (Maine and Kimble, 1989) \\
\hline & glp-1(ar202)ts & Fertile at $20^{\circ} \mathrm{C}$ & (Pepper et al., 2003a) \\
\hline & & Germline tumors at $25^{\circ} \mathrm{C}$ & \\
\hline \multirow[t]{6}{*}{ Ras-ERK MAPK signaling } & $m p k-1(g a 117)$ & Pachytene arrest and sterile & (Lackner and Kim, 1998) \\
\hline & $m p k-1$ (ga111)ts & Pachytene arrest and sterile at $25^{\circ} \mathrm{C}$ & (Lackner and Kim, 1998) \\
\hline & let-60(n1046) & Multi-layered small oocytes and & (Hajnal and Berset, 2002) \\
\hline & & Multivulva (Muv) phenotype & (Beitel et al., 1990) \\
\hline & puf-8(q725); lip-1(zh15) & Mog sterile at $20^{\circ} \mathrm{C}$ & (Morgan et al., 2010) \\
\hline & & Germline tumors at $25^{\circ} \mathrm{C}$ & (Cha et al., 2012) \\
\hline
\end{tabular}

review focuses chiefly on canonical Wnt/ $\beta$-catenin signaling that specifies a germline stem cell niche (known as a DTC in C. elegans) fate specification in the C. elegans gonad (Fig. 2D). The DTC functions as the germline stem cell niche, which is essential for germline stem cell maintenance (Kimble and Crittenden, 2007). During early larval development, the DTC arises initially from an asymmetric cell division of a somatic gonadal progenitor (SGP) cell (Fig. 2C). This division specifies one daughter DTC potential and another non-DTC potential (Kimble and Crittenden, 2007; Byrd et al., 2014). In hermaphrodites, the DTC potential divides asymmetrically once more to differentiate terminally to form the DTC. The DTC fate is specified by divergent Wnt/ $\beta$-catenin signaling pathways (Fig. $2 \mathrm{C})$. The pathway regulating the asymmetric division of precursor cells, Z1 and Z4, involves Frizzled receptors (LIN-17 and MOM-5), Dishevelled proteins (DSH-2 and MIG-5), $\beta$-catenin (SYS-1), and TCF transcription factor (POP-1) (Kimble and Crittenden, 2007; Byrd et al., 2014) (Fig. 2C). Aberrant regulation of this pathway results in either the loss of DTC fate (Fig. 2E) or the generation of extra DTCs by symmetric division (Fig. 2F). Importantly, POP-1/TCF and SYS-1/ $\beta$-catenin directly activate the transcription of ceh-22 (Nkx2.5 homolog in mammals) in DTC potentials (Lam et al., 2006) (Fig. 2C). CEH-22/Nkx2.5 is necessary for DTC specification (Lam et al., 2006). Therefore, Wnt/ $\beta$-catenin signaling and its direct targets (e.g., CEH-22) play an essential role in DTC fate specification in the $C$. elegans gonads (Fig. 2C-2F).

\section{Phenotype-based drug screening for Wnt/ $\beta$-catenin signaling mutants}

In C. elegans, the DTC functions as a germline stem cell niche, and it employs GLP-1/Notch signaling to promote continued mitotic divisions. The DTC fate is regulated by $\mathrm{Wnt} / \beta$ catenin signaling and its direct target, CEH-22/Nkx2.5 (Lam et al., 2006; Kimble and Crittenden, 2007). Therefore, weak or no Wnt signaling results in DTC loss and consequently no germline stem cells, which cause either partially or completely sterile (Fig. 2E). To visualize DTCs, a molecular marker lag-
2::GFP reporter gene can be used. This GFP marker is expressed brightly in DTCs (Fig. 2D, see green) (Blelloch and Kimble, 1999). The lag-2 is one of C. elegans Notch ligands and expressed in the DTC (Henderson et al., 1994; Blelloch et al., 1999). Normally, wild-type hermaphrodites have two DTCs (Byrd and Kimble, 2009) (Fig. 2D). However, loss of POP-1, SYS-1 or CEH-22 eliminates DTC fate (Fig. 2E), and ectopic SYS-1 or CEH-22 produces extra DTCs and generates new germline stem cell populations (Fig. 2F, Table 1) (Kimble and Crittenden, 2007; Byrd et al., 2014). Indeed, the ceh-22 gene is a direct target of transcriptional activation by POP-1/ TCF and SYS- $1 / \beta$-catenin (Fig. 2C) (Lam et al., 2006) and is expressed in the cells with DTC potential (Lam et al., 2006). Notably, about $40 \%$ of ceh-22 mutants are missing both DTCs and are completely sterile. $40 \%$ of them are missing one of two DTCs and are partially sterile, and $20 \%$ of them produce two DTCs and are fertile (Lam et al., 2006). Amazingly, ectopic expression of ceh-22 gene produces extra DTCs (Fig. 2F, Table 1) (Lam et al., 2006). Therefore, ceh-22 (q632) lossof-function mutant is an attractive allele to identify drugs that can inhibit or activate the $\mathrm{Wnt} / \beta$-catenin signaling pathway. If a drug inhibits Wnt/ $\beta$-catenin directly or indirectly, it will enhance DTC loss and produce the sterile phenotype of ceh-22 mutants (Fig. 2G left). By contrast, if the drug activates Wnt/ $\beta$-catenin signaling, it will retain the fertility of ceh-22 mutants and will result in two or more DTCs (Fig. $2 \mathrm{G}$ right). Furthermore, if the drug suppresses the inhibitor of $W n t / \beta$-catenin signaling directly or indirectly, it can activate $W n t / \beta$-catenin signaling and may retain the fertility of ceh-22 mutants. The DTC fate is also regulated at least in part by cell cycle regulators. Tilmann and Kimble have previously reported that Cyclin $D$ is required for DTC fate specification (Tilmann and Kimble, 2005). Moreover, we also found that cell cycle regulators work together with $W n t / \beta$-catenin signaling to specify DTC fate (Lee et al., 2014). Therefore, it suggests a possibility that the identified drugs can target the cell cycle regulators and/or Wnt/ $\beta$-catenin signaling. The specificity can be examined by chemical genetics in $W n t / \beta$-catenin mutants or cell cycle mutants. Therefore, 
Kobet et al. C. elegans as a Model System for the Identification of Drugs and Therapeutic Targets

diverse $C$. elegans mutants for $W n t / \beta$-catenin signaling will provide a great opportunity to identify drugs that can potentially treat $\mathrm{Wnt} / \beta$-catenin signaling-associated human diseases such as colon cancer.

\section{ONCOGENIC PATHWAYS: NOTCH SIGNALING}

\section{Overview of Notch signaling}

In most multicellular organisms, the Notch signaling pathway is a highly conserved signaling pathway that controls proliferation, differentiation, cell fate specification, and apoptosis (Artavanis-Tsakonas et al., 1999). Notch and most of its ligands (DSL: Delta/Serrate/LAG-2) are trans-membrane proteins. Notch ligands are expressed in the cells that are adjacent to the Notch expressing cells. In absence of Notch ligand, CSL (CBF1, Suppressor of Hairless, LAG-1) transcription factors are associated with co-repressors (Fig. 3A). This complex inhibits the expression of Notch target genes (Fig. $3 A)$. Once the Notch interacts with a ligand, an ADAM-family metalloprotease cleaves the outside of Notch receptor (Fig. 3B). After this cleavage, $\gamma$-secretase cleaves the remaining part of the Notch receptor inside the inner leaflet of the cell membrane (Fig. 3B). This releases the intracellular domain of the Notch (NICD), which then translocates to the nucleus (Fig. 3B). In the nucleus, the NICD forms a complex with CSL (CBF1, Suppressor of Hairless, LAG-1) transcription factors and mastermind-like protein (MAML-1) to activate the expression of target genes (Fig. 3B). Importantly, an aberrant Notch signaling pathway potentially contributes to cancer development in several different ways (Allenspach et al., 2002) or to loss of the specific cell type (Liu et al., 2010). Therefore, the Notch signaling pathway represents a novel target for cancer therapeutic intervention and regenerative medicine.

\section{Notch signaling and cancer stem cells}

Aberrant activation of Notch signaling has been detected in a variety of human cancers including pancreatic cancer (Ristorcelli and Lombardo, 2010; Avila and Kissil, 2013), colon cancer (Miyamoto and Rosenberg, 2011), osteosarcoma (Hughes, 2009), glioblastoma (Lino et al., 2010), lung cancer (Galluzzo and Bocchetta, 2011), head and neck cancer (Sun et al., 2014), and breast cancer (Reedijk, 2012). Notably, activation mutations of human Notch1 are reported in approximately $50 \%$ of T-ALL (acute lymphoblastic leukemia) cases (Ferrando, 2009). The role of Notch in stem cell regulations has been thoroughly studied in several model systems to date. Moreover, the role of the Notch signaling in the initiation and maintenance of cancer stem cells has recently become a subject of study in a number of diverse model organisms. For example, Notch signaling is upregulated in pancreatic cancer stem cells (Abel et al., 2014). Reduction of the Notch signaling by either genetic inhibition (e.g. Hes1 shRNA) or drug treatment (e.g., $\gamma$-secretase inhibitor) in pancreatic cancer decreased cancer stem cell population and tumorsphere formation (Abel et al., 2014). In addition, the inhibition of Notch signaling by treatment with GSI-18 ( $\gamma$-secretase inhibitor) depleted the stem cell-like subpopulation derived from medulloblastoma cell lines and abolished xenograft formation (Fan et al., 2006). By contrast, the activation of the Notch signaling pathway with DSL peptide stimulated tumorsphere formation and increased cancer stem cell population (Abel et al., 2014).
Bao et al. also reported that Notch-1 activation induced cancer stem cell self-renewal capacity through epithelial-mesenchymal transition (EMT) (Bao et al., 2011). Therefore, the Notch signaling pathway is important in maintaining cancer stem cell population, and targeting its pathway in cancer has promising therapeutic potential.

\section{C. elegans Notch signaling}

The Notch signaling pathway and its core components in $C$. elegans are highly conserved. The $C$. elegans has two Notch receptors, GLP-1 and LIN-12, which mediate cell-cell interaction during development (Greenwald, 2005). Specifically, GLP-1/Notch signaling in the $C$. elegans germline is critical for germline stem cell maintenance and continued mitotic division (Kimble and Crittenden, 2007). LIN-12/Notch signaling in the $C$. elegans somatic cells specifies vulva cell fate during early larval stages (Greenwald, 2005). When LAG-2 (GLP-1/ Notch ligand) is expressed in DTCs (Fig. 3C) (Henderson et al., 1994) and interacts with the GLP-1/Notch receptor, proteolytic cleavage of the GLP-1/Notch receptor follows (Fig. $3 C)$. GLP-1/Notch intracellular domain (NICD) is then translocated from the membrane into the nucleus (Fig. $3 \mathrm{C}$ ). In the nucleus, the NICD forms a tertiary complex with LAG-1/CSL DNA binding protein and LAG-3/SEL-8/Mastermind transcription co-activator to activate the expression of target genes: fbf-2 (PUF RNA-binding protein) (Lamont et al., 2004) and lip1 (MAPK phosphatase) (Berset et al., 2001; Lee et al., 2006), Ist-1 (Nanos-like zinc finger domain-containing protein) (Yoo et al., 2004; Kershner et al., 2014), and sygl-1 (Novel protein) (Kershner et al., 2014) (Fig. 3C). Importantly, FBF-2, and LIP1 inhibit meiosis-promoting regulators (e.g., GLD-1, GLD-2, GLD-3, and MPK-1) in the C. elegans germline (Yoo et al., 2004; Lee et al., 2006; Kimble and Crittenden, 2007; Lee et al., 2007a). Therefore, loss of GLP-1/Notch signaling in germline causes a severe proliferation defect during early meiotic entry, resulting in no germline stem cell maintenance and sterility (Fig. 3D) (Austin and Kimble, 1987), while constitutive activation of this signaling promotes proliferation of germline stem cells and their progenitor cells as well as inhibits entry into meiosis, resulting in germline tumors and sterility (Fig. 3E) (Berry et al., 1997). Therefore, the aberrant regulation of GLP$1 /$ Notch signaling can cause either loss of germline stem cells or overproliferation of a specific cell type, resulting in sterility.

\section{Phenotype-based drug discovery for Notch signaling using glp-1 mutants}

The $C$. elegans has multiple Notch mutants, including glp-1(q46) or glp-1(q175) null mutants, glp-1(bn18 or q224) temperature-sensitive (ts), loss-of-function (If) mutants, and glp-1(ar202) temperature sensitive (ts), gain-of-function (gf) mutant (Table 1). In C. elegans germline, GLP-1/Notch signaling is essential for germline stem cell maintenance and mitotic germ cell proliferation (Kimble and Crittenden, 2007). For example, at $20^{\circ} \mathrm{C}$ or lower, temperature sensitive, lossof-function mutants for $g l p-1$, "glp-1(bn18) and $g / p-1(q 224)$ " produce sperm and oocytes and are therefore fertile (Fig. 3D and $3 \mathrm{E}$ left). Conversely, at $25^{\circ} \mathrm{C}$, they have a severe proliferation defect and early meiotic entry (Fig. 3D right). However, a temperature sensitive, gain-of-function mutant for $g / p-1$, "glp-1(ar202)" with constitutively active GLP-1/Notch signaling promotes proliferation of germline stem cells and inhibits entry into meiosis, resulting in germline tumors at $25^{\circ} \mathrm{C}$ (Fig. 


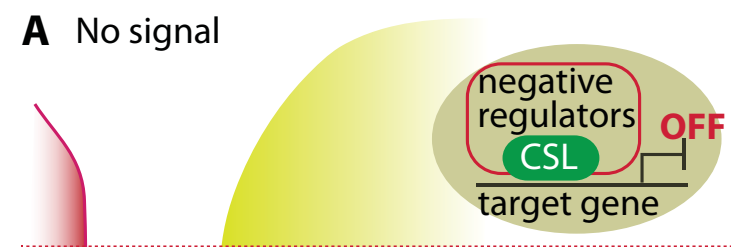

\section{C. elegans GLP-1/Notch signaling}
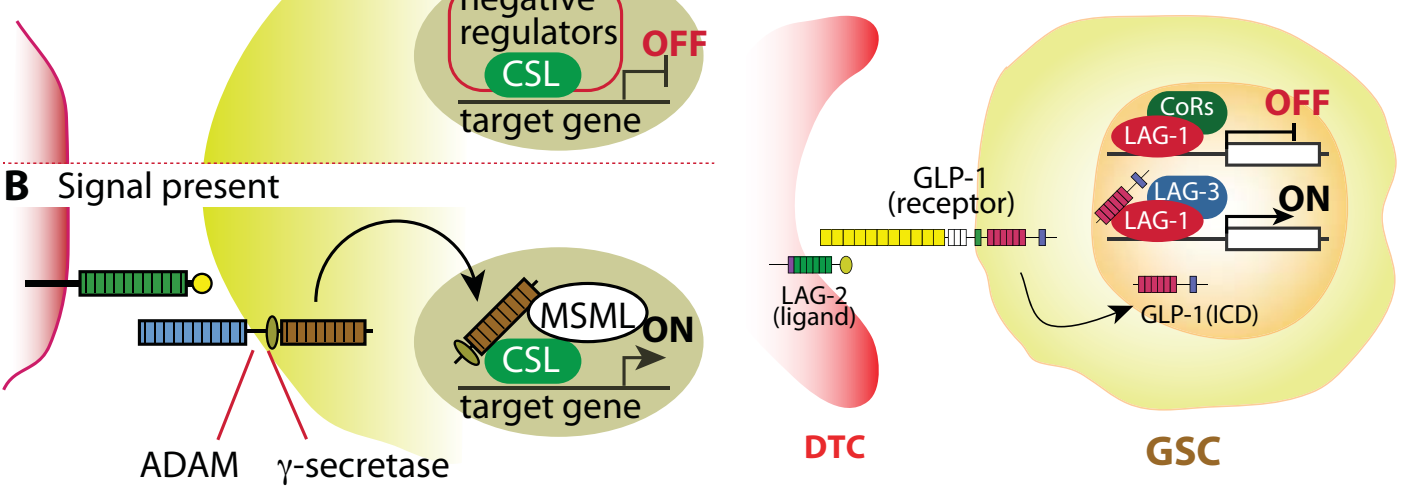

D. Temperature-sensitive, loss-of-function glp-1 mutants (e.g., glp-1(bn18))

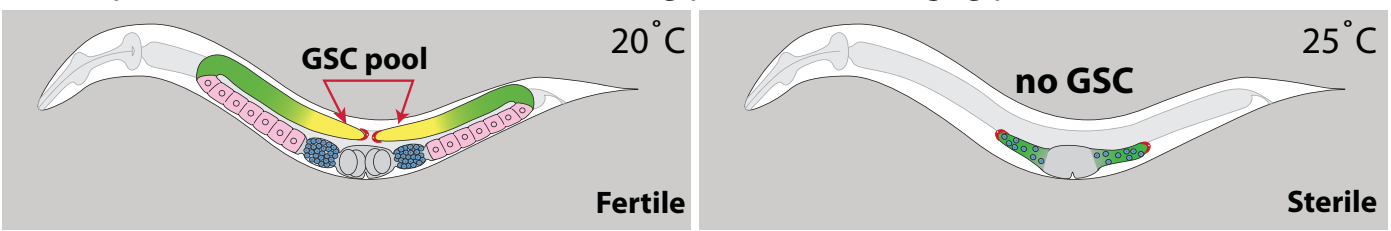

E. Temperature-sensitive, gain-of-function glp-1 mutants (e.g., glp-1(ar202))

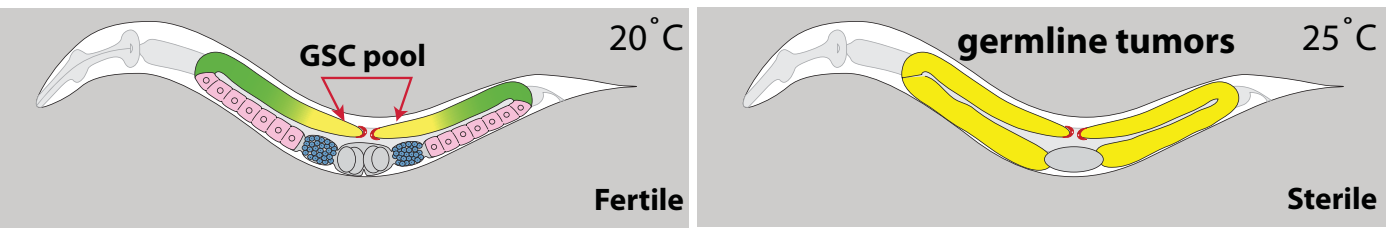

F. Drug screening for Notch signaling

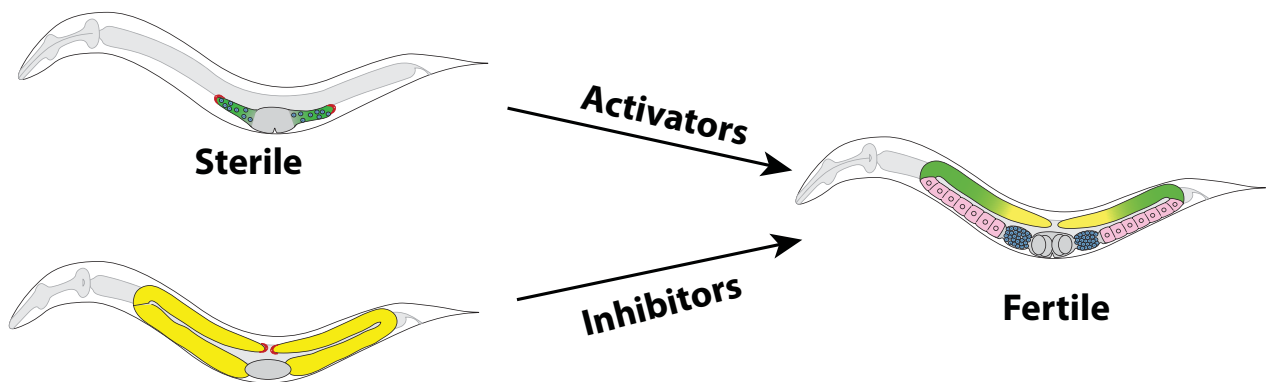

Sterile

Fig. 3. Notch signaling pathways and a strategy for the phenotype-based drug identification using C. elegans mutants. (A) Without signaling, negative regulators inhibit the expression of Notch target genes. (B) With signaling, cleaved NICD transports from membrane to nucleus. In nucleus, NICD form a ternary complex with CSL and co-activator, mastermine-like protein, to activate the expression of target genes. (C) C. elegans GLP-1/Notch signaling pathways. The DTC expresses GLP-1/Notch ligands (e.g., LAG-2) and employs GLP-1/Notch signaling to promote continued mitotic divisions. (D) In mutants lacking any of the core elements of the GLP-1/Notch signaling pathways (e.g., glp-1 loss-of-function mutant), germ cells leave the mitotic cell cycle, enter meiosis, and undergo gametogenesis, resulting in no germline stem cells and sterility. Most temperature-sensitive glp-1(bn18) loss-of-function mutants are fertile at $20^{\circ} \mathrm{C}$, but they are sterile at $25^{\circ} \mathrm{C}$. (E) Constitutively active GLP-1/Notch signaling develop germline tumors. Most temperature-sensitive g/p-1(ar202) gain-of-function mutants are fertile at $20^{\circ} \mathrm{C}$, but they are sterile due to germline tumors at $25^{\circ} \mathrm{C}$. $(F)$ Strategy for the phenotype-based identification of drugs that either inhibit or activate Notch signaling using $C$. elegans mutants.

3E right) (Pepper et al., 2003b). Notably, this germline tumor phenotype is rescued by the depletion of GLP-1/Notch signaling component genes, including LAG-3/SEL-8/mastermind (Petcherski and Kimble, 2000). Therefore, glp-1(If) or glp-1(gf) mutants are useful animals for the identification of drugs that may target GLP-1/Notch signaling positively or negatively (Fig. $3 F)$. The specificity can be tested by measuring the expression of direct GLP-1/Notch signaling target genes (e.g., fbf-2, lip-1, 
Kobet et al. C. elegans as a Model System for the Identification of Drugs and Therapeutic Targets

Ist-1, or sygl-1) (Lamont et al., 2004; Lee et al., 2006; Kershner et al., 2014) or by analyzing the effect of drugs on GLP-1/ Notch-unrelated synthetic mutants with germline tumors (e.g., gld-3, nos-3) (Eckmann et al., 2002). Together, C. elegans GLP-1/Notch signaling pathways and their core components are highly conserved in vertebrates, including humans. Therefore, the identification and characterization of such drugs will provide a tremendous promise for cancer therapy.

\section{ONCOGENIC PATHWAYS: RAS SIGNALING}

\section{Overview of Ras signaling pathway}

Ras-ERK MAP (Mitogen Activated Protein) kinase (MAPK) signaling pathways are highly conserved in all eukaryotes and are involved in numerous cellular responses including proliferation, differentiation, cell fate specification, cellular homeostasis, and survival (Fig. 4A) (Marshall, 1995; Whelan et al., 2012). Extracellular stimuli such as growth hormone activate Ras-ERK MAPK signaling through a MAPK signaling cascade. In short, extracellular ligands bind to the epidermal growth factor receptor (EGFR) and activate tyrosine kinase activity of the cytoplasmic domain of the EGFR (Fig. 4A). The EGFR-binding adaptor, Grb2, binds to the phosphotyrosine residues of the activated receptor (Schulze et al., 2005) and to the guanine nucleotide exchange factor, SOS, through two $\mathrm{SH} 3$ domains of GRB2. This Grb2/SOS complex when docked to phosphorylated EGFR is activated, which then promotes the activation of Ras proteins (Fig. 4A). Activated Ras phosphorylates and activates RAF kinase, activated RAF phosphorylates and activates MEK, and activated MEK phosphorylates and activates ERK MAPK (Fig. 4A). Finally, activated ERK MAPK regulates its downstream targets in the positive or negative manners by phosphorylation (Fig. 4A). The downstream targets include transcription regulators (e.g., GATA-1) (Towatari et al., 2004), translational regulators (e.g., p90 ribosomal S6 kinases: RSK1, 2, 3) (Zhao et al., 1996), cell cycle regulators (e.g., Cyclin D1) (Okabe et al., 2006), and apoptosis regulators (e.g., BCL-2) (Tamura et al., 2004). Therefore, aberrant activation of Ras-ERK MAPK signaling contributes to abnormal gene expression, cell cycle progression, proliferation, and survival. Notably, a constitutively active Ras-ERK MAPK signaling has been shown to lead to the development of all cancers (Saxena et al., 2008). Therefore, the drugs that target Ras-ERK MAPK signaling are potential drugs for treating cancer.

\section{Ras signaling and cancer stem cells}

The Ras-ERK MAPK signaling pathway governs many cellular processes in most animals and is deregulated in approximately one-third of all human cancers. Because of its importance in cancer, the Ras-ERK MAPK signaling pathway has been an attractive target for anti-cancer therapy. For example, Moon et al examined the role of two genes, APC and K-Ras, working in tandem in initiating colorectal cancer progression (Moon et al., 2014). The group's data showed that a gain-offunction mutation of the oncogenic K-Ras, fixing it in the active, GTP-bound conformation, accelerates the ERK pathway, which in turn activates the Wnt/ $\beta$-catenin pathway, inducing cancer stem cell marker expression in colorectal cancer cells (Moon et al., 2014). Increased contribution to tumorigenesis and liver metastasis in K-Ras ( $g f$ ) was observed in the pres- ence of loss-of-function mutations in adenomatous polyposis coli $(A P C)$, a negative regulator of $\beta$-catenin concentration, another condition characteristic of initial and intermediate stage colorectal cancer (Moon et al., 2014). The study utilized specimens from human colorectal cancer patients and $A P C^{\mathrm{Min} /+} / \mathrm{K}-\operatorname{Ras}^{\mathrm{LA2}}$ mice, which were studied for their ability to form spheroids in vitro and tumors in vivo, respectively. A mouse xenograft model was also utilized using wild-type $K$ Ras and mutant $K$-Ras cells to observe cancer stem cell activation as a result of $K$-Ras mutation. Therefore, Ras activation can initiate the formation of cancer stem cells through Wnt/ $\beta$ catenin activation.

\section{C. elegans Ras signaling}

The Ras-ERK MAPK signaling pathways governs many cellular processes, including proliferation, differentiation, cell fate specification, homeostasis, and survival in all eukaryotes. The Ras-ERK MAPK signaling pathways in the C. elegans germline are well described by Sundaram (Sundaram, 2006). Notably, core signaling pathways and their components are strikingly conserved (Fig. 4B) (Sundaram, 2006; Whelan et al., 2012). Briefly, two different RTKs, LET-23 (an EGFR homolog) and EGL-15 (a FGFR homolog) stimulate LET-60 (a Ras homolog) and its downstream cascade, consisting of LIN-45 (a Raf homolog), MEK2 (an MEK homolog) and MPK-1 (an ERK homolog) (Fig. 4B). This C. elegans Ras-ERK MAPK signaling controls multiple developmental events, including meiotic cycle progression, oocyte activation, sperm fate specification, spermatogenesis, physiological apoptosis, axon guidance, and vulva development (Lee et al., 2006; Sundaram, 2006; Lee et al., 2007b; Morgan et al., 2010) (Fig. 4B). In wild-type C. elegans hermaphrodite germline, activated MPK-1/ERK was not detected in the distal germline (e.g., germline stem cell region and pre-meiotic region) but became abundant in the proximal part of the pachytene region and in maturing oocytes (Lee et al., 2007a; Lee et al., 2007b) (Fig. 4C). Activated MPK-1/ERK is subject to two redundant modes of downregulation in the germline stem cell region: FBF-1/-2 (members of PUF RNA-binding protein family) proteins act post-transcriptionally to repress $m p k-1 / E R K$ mRNA and LIP-1 acts posttranslationally to inhibit MPK-1/ERK activity (Fig. 4C) (Lee et al., 2007a). This regulation is also conserved in human embryonic stem cells (Lee et al., 2007a; Whelan et al., 2012). Therefore, the dual negative regulation of MAPK/ERK by both PUF repression and MKP (MAPK phosphatase) inhibition may be a conserved mechanism that influences both stem cell maintenance and possibly tumor progression (Whelan et al., 2012). In $C$. elegans germline, additional regulators have also been identified as inhibitors of $C$. elegans Ras-ERK MAPK signaling: LARP-1 (La-related protein) and Insulin signaling inhibit Ras-ERK MAPK signaling during oogenesis (Nykamp et al., 2008; Lopez et al., 2013). PUF-8 (a member of PUF protein family) represses let-60/Ras mRNA expression in the germline stem cell region (Vaid et al., 2013). The germline center kinase (GCK1) also represses apoptosis by inhibiting Ras-ERK MAPK signaling (Schouest et al., 2009). Therefore, the RasERK MAPK signaling is regulated positively or negatively by several regulators, including kinases, phosphatases, or RNA regulators. 


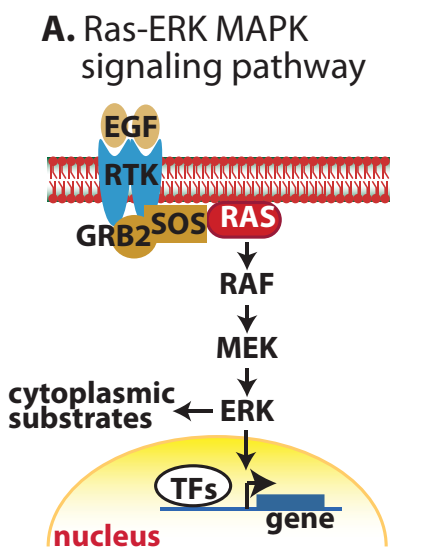

TFs: transcriptional factors

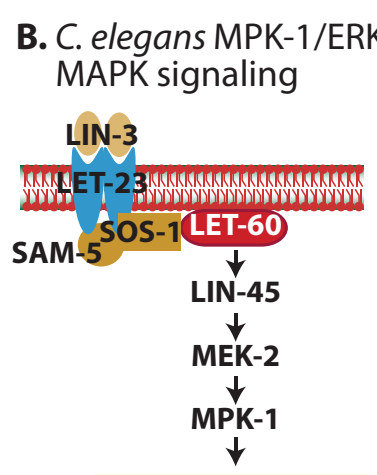

Meiotic progression Oocyte maturation Sperm fate specification Apoptosis, etc

\section{Active MPK-1/ERK}

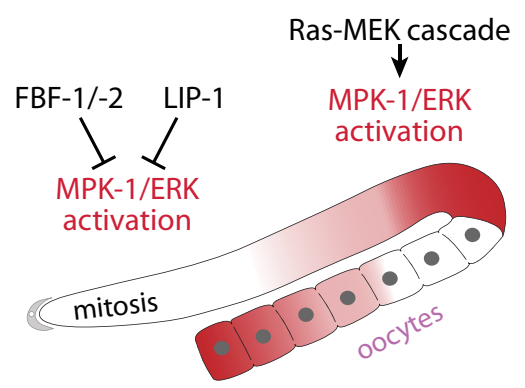

D. Temperature-sensitive, loss-of-function mpk-1 mutant (e.g., mpk-1(ga111))

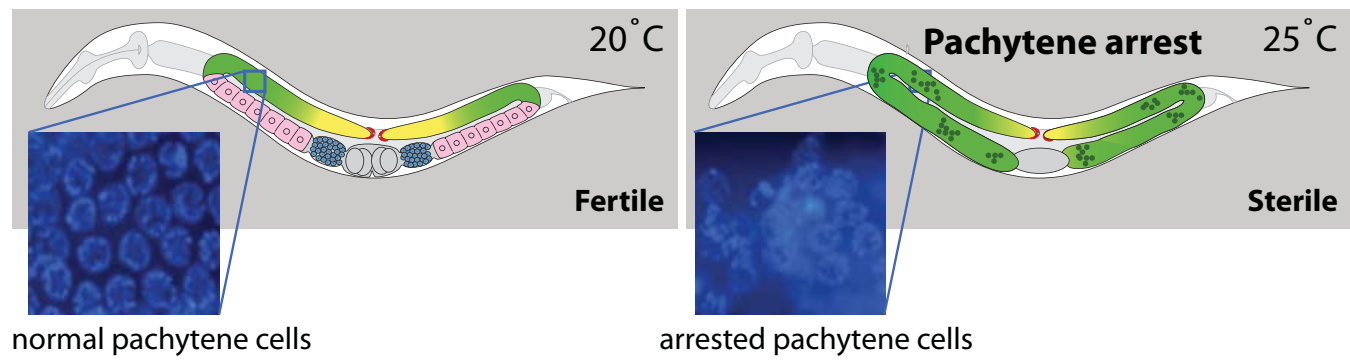

E. puf-8; lip-1 mutant

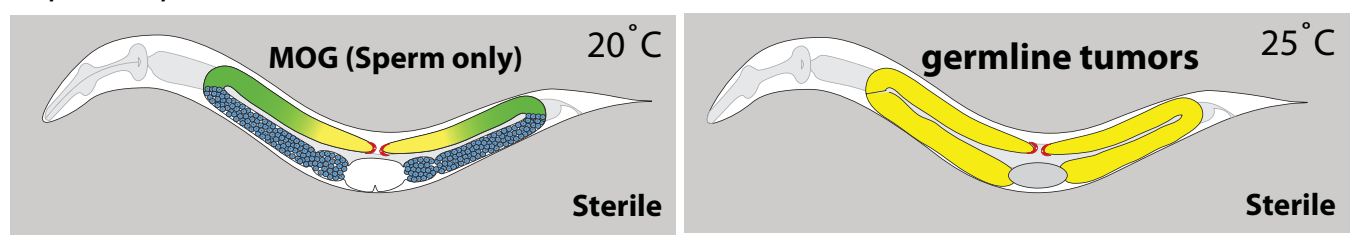

F. Drug screening for Ras signaling
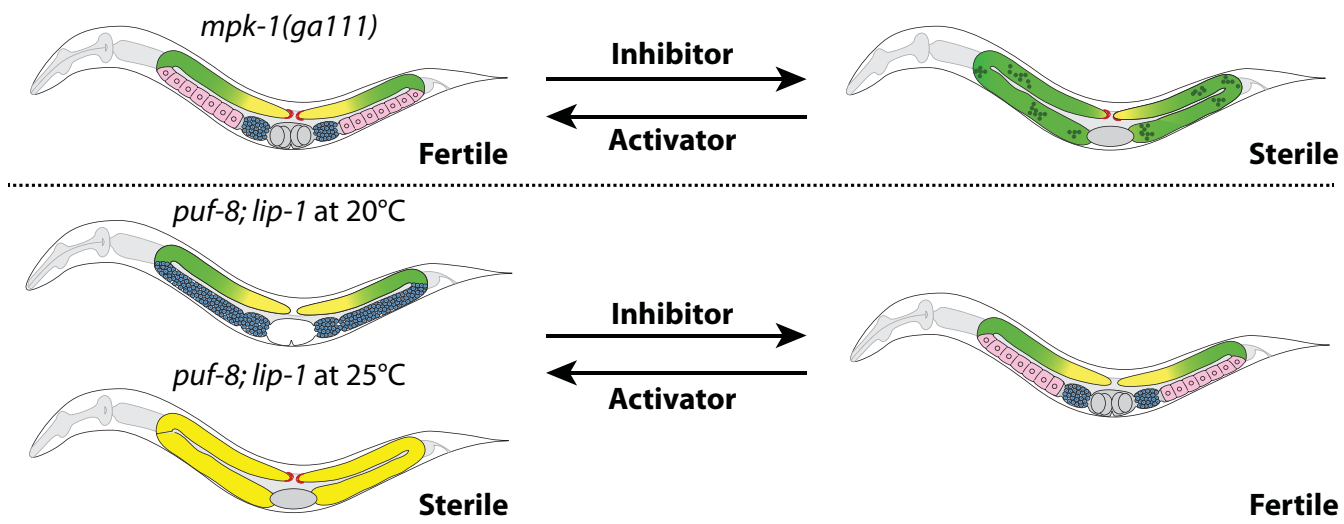

Sterile

Fertile

Fig. 4. Ras signaling pathways and a strategy for the phenotype-based drug identification using $C$. elegans mutants. (A) Conserved Ras-ERK MAPK signaling pathways. (B) C. elegans Ras-ERK MAPK signaling pathway. (C) Schematic of adult wild-type hermaphrodite germline. MPK-1/ERK is activated in the proximal pachytene and developing oocytes (see red). In the distal germline, FBF-1/-2 and LIP-1 repress MPK-1/ERK activation at the post-transcriptional and translational levels (Lee et al., 2007a). (D) The germline phenotype of temperature-sensitive $m p k-1$ (ga111) loss-of-function mutant. At $20^{\circ} \mathrm{C}$, most $m p k-1$ (ga111) mutants are fertile, but they are sterile due to pachytene arrest at $25^{\circ} \mathrm{C}$. DAPI staining shows normal pachytene cells (left) and arrested pachytene cells (right). (E) The germline phenotype of puf-8; lip-1 homozygote mutant at $20^{\circ} \mathrm{C}$ (left) and $25^{\circ} \mathrm{C}$ (right). The puf-8; lip-1 mutants produce only sperm (Mog phenotype) at $20^{\circ} \mathrm{C}$, but spermatocytes are dedifferentiated into mitotically dividing cells, resulting in germline tumors at $25^{\circ} \mathrm{C}$. $(\mathrm{F})$ Strategy for the phenotype-based identification of drugs that either inhibit or activate Ras-ERK MAPK signaling using $C$. elegans mutants. 

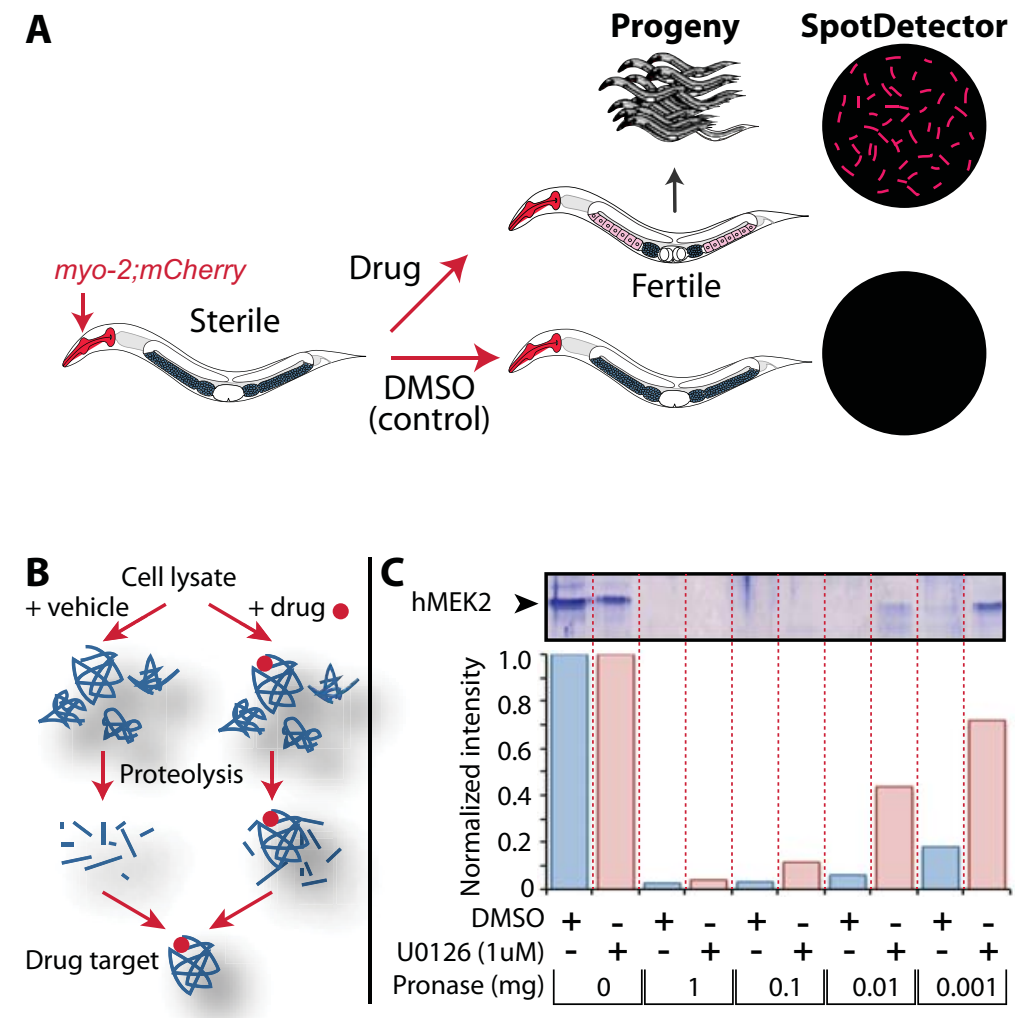

Fig. 5. Fertility and image-based high-throughput screening and In vitro DARTS using human MEK2 (hMEK2). (A) Fertility and imagebased high-throughput drug screening. Slightly modified from (Benson et al., 2014). Fluorescence images can be taken on the Arrayscan $\mathrm{V}^{\mathrm{t}} /$ SpotDetector can identify numerous progeny in wells treated with drugs and DMSO control. (B) Scheme of DARTS. (C) U0126 protects hMEK2 from pronase degradation. In vitro DARTS technique was optimized using a purified GST-tagged human MEK2 (hMEK2) protein with U0126, a well-known MEK2 inhibitor and DMSO. U0126 stabilizes hMEK2 from 0.001 mg pronase.

\section{Phenotype-based drug discovery for Ras signaling using mpk-1 or puf-8; lip-1 mutants}

Loss of Ras-ERK MAPK signaling results in germline sterility due to abnormal meiotic progression and gametogenesis (Lee et al., 2007b). Intriguingly, this sterility phenotype was rescued by the inhibition of negative Ras-ERK MAPK regulators (e.g., LIP-1) (Hajnal and Berset, 2002; Lee et al., 2006). In contrast, aberrant activation of Ras-ERK MAPK by removal of PUF-8 and LIP-1 promotes sperm fate at $20^{\circ} \mathrm{C}$ (Morgan et al., 2010) and induces germline tumors at $25^{\circ} \mathrm{C}$ (Cha et al., 2012). For example, a temperature sensitive, mpk-1(ga111) loss-of-function mutant is mostly fertile at $20^{\circ} \mathrm{C}$, but it is sterile at $25^{\circ} \mathrm{C}$ due to pachytene arrest (Fig. 4D). This sterile phenotype is rescued by the depletion of MPK-1 inhibitors (e.g., LIP-1) (Hajnal and Berset, 2002; Lee et al., 2006). In addition, activated MPK-1/ERK in puf-8; lip-1 mutant promotes spermatogenesis without switching into oogenesis (Masculinization of germline (Mog) phenotype) at $20^{\circ} \mathrm{C}$ and develops germline tumors via dedifferentiation of spermatocytes at $25^{\circ} \mathrm{C}$ (Fig. 4E) (Morgan et al., 2010; Cha et al., 2012; Datla et al., 2014). Surprisingly, inhibition of Ras-ERK MAPK signaling by either genetic mutation or drug treatment (e.g., U0126) sufficiently rescued puf-8; lip-1 sterility (Morgan et al., 2010; Cha et al., 2012; Datla et al., 2014). Therefore, mpk-1(If) mutants and puf-8; lip-1 mutants (Table 1) are useful animals for the identification of drugs that may target Ras-ERK MAPK signaling positively or negatively (Fig. 4F). The specificity can be confirmed using let-60(n1046) gain-of-function mutant or a transgenic worm expressing LET-23 chimeras in which the TK domain was replaced with the human mutant TK domain (L858R or T790M-L858R). Both animals with hyperactive RasERK MAPK signaling in somatic vulva precursor cells induce a multivulva (Muv) phenotype. Notably, these muv phenotypes were rescued by the treatment of Ras-ERK MAPK inhibitors, including AG1478 (an EGFR-TK inhibitor), U0126 (a MEK inhibitor), Gefitinib, Manumycin, and Gliotoxin (Hara and Han, 1995; Bae et al., 2012). Therefore, mutants and transgenic animals are a model system that can be used in signaling or mutation-specific screens for new anti-cancer drugs.

\section{FERTILITY-BASED IN VIVO HIGH-THROUGHPUT DRUG SCREENING AND DRUG TARGET IDENTIFICATION}

For large-scale high-throughput drug screening, we have recently developed a fertility and image-based, label-free high-throughput workflow (Benson et al., 2014). This automated high-content assay enables effect sorting of $C$. elegans mutants into a 384-well plate using the COPAS ${ }^{\mathrm{TM}}$ Worm Sorter and rapidly measuring either fertility or sterility by scoring the number of viable progeny in wells (Benson et al., 2014). For example, homozygote mutants for puf-8; lip-1 
are sterile and must be maintained as heterozygotes using a GFP-tagged balancer chromosome for chromosome II (e.g., $\mathrm{mln}$ [m/s14(Pmyo-2::GFP) dpy-10(e128), called mc6g). Homozygotes for experiments are typically selected by picking GFPnegative mutants using a fluorescence microscope. However, for large-scale animal handling, it would be advantageous to automatically identify homozygote mutants using a fluorescent marker. To this end, we generated a puf-8/mc6g; lip-1/ lip-1; $\left[P_{\text {myo-2 }}:: m\right.$ Cherry $]$ transgenic mutant strain expressing a red-fluorescent protein, mCherry, in the head (Fig. 5A). The incorporation of the red-head marker, allows effective isolation of homozygote puf-8; lip-1 mutants [GFP(-) and mCherry(+)] using an automatic worm sorter, COPAS ${ }^{\mathrm{TM}}$ BIOSORT. Furthermore, the mCherry head marker also simplifies detection of puf-8; lip-1 progeny that is difficult to identify using bright field optics (Fig. 5A). For fertility and image-based high-throughput drug screening, mutants of Wnt, Notch, or Ras signaling pathways can be incorporated with the red-head marker (mCherry), which allows to measure automatically either fertility or sterility by scoring the number of viable progeny in wells using Arrayscan Vti/SpotDetector (Benson et al., 2014). Detail methods are described in Benson et al (Benson et al., 2014).

To date, several drugs that target core components of each oncogenic signaling pathways through target-specific in vitro screening. Nontheless, the drugs also alter normal signaling pathways. Moreover, current affinity-based target identification approaches require each drug of interest to be immobilized to a bead or another affinity- or fluorescent- or radioactive-"tag" so that the target protein can be "pulled down". However, the coupling of compounds to beads and other molecules could lead to alteration or loss of compound bioactivity and binding. Furthermore, these techniques are time-consuming and require extensive biochemistry or medicinal chemistry expertise (Lomenick et al., 2009; Lomenick et al., 2011). Recently, Huang and colleagues reported that the molecular target of the identified drug could be identified using a newly developed technique, called Drug Affinity Responsive Target Stability (DARTS) (Fig. 5B) (Lomenick et al., 2009; Lomenick et al., 2011). DARTS takes advantage of the concept that protease susceptibility of the target protein is reduced upon drug binding (Lomenick et al., 2009; Lomenick et al., 2011). The advantage of this approach is that it is universally applicable as modification of the drug is not necessary and is independent of the mechanism of drug action. In particular, The DARTS is useful for the initial identification of the targets of compounds, but can also be useful for validation of potential proteinligand interaction (Lomenick et al., 2011). To test whether the DARTS is useful for molecular target identification of the identified drugs, we established an in vitro DARTS technique using a purified GST-tagged human MEK2 (hMEK2) protein with U0126, a well-known MEK2 inhibitor (Duncia et al., 1998; Favata et al., 1998) and DMSO (control) (Fig. 5C). Interestingly, U0126 (1 uM) stabilized MEK2 protein, thereby reducing protease (pronase) sensitivity of the MEK2 protein (Fig. 5C). Although DARTS is a suitable and feasible method to identify the oncogenic target of the drugs, it remains still a major challenge if this method can be applied for all drug targets.

\section{CONCLUSIONS}

In this review, we describe three conserved oncogenic signaling pathways that are often associated with the development of cancer stem cells. Importantly, these signaling pathways are highly conserved and critical for germline development in C. elegans. Therefore, aberrant regulations of these signaling pathways cause either partially or completely sterile. Notably, inhibition or activation of these signaling pathways by drug treatment retains fertility (Morgan et al., 2010; Benson et al., 2014). Based on this finding, we here propose possible phenotype-based high-throughput screening methods to identify drugs that may alter oncogenic signaling pathways. The identification of drugs is a powerful tool of biological analysis and therapeutics as well as can lead to the development of new drugs. However, a critical bottleneck is generating useful drug tools is target identification. Current target identification techniques have several limitations. For example, affinity-based target identification is limited by the necessary to modify each individual without losing bioactivity, and nonaffinity-based approaches depend on the drug's ability to induce specific biochemical or cellular readouts (Lomenick et al., 2009; Lomenick et al., 2011). Recently, Huang and colleagues established DARTS as a new technique (Lomenick et al., 2009; Lomenick et al., 2011). This technique is able to identify the targets of drugs based on the principle that when a drug binds to a protein, the interaction stabilizes the target protein's structure, resulting in proteolytic resistance (Lomenick et al., 2009; Lomenick et al., 2011). If the specific targets of drugs are identified by DARTS technique, the peptides can be identified by mass-spectrometry after trypsin digestion. Therefore, these approaches, described in this review, have great potential for finding new drugs and will also aid research in cancer therapies.

C. elegans has also emerged as an attractive model system for functional analyses of bioactive compounds (e.g., nicotine) and natural components. Previously, Xu and colleagues developed a C. elegans model of nicotine-dependent behavior (Feng et al., 2006). They showed that $C$. elegans displays acute and chronic behavioral responses through nAChRs (nicotinic acetylcholine receptor, acr-5 and acr-15 in C. elegans) that are known to be critical for nicotine dependence in mammals (Feng et al., 2006; Sellings et al., 2013). In addition, chronic nicotine exposure can alter the expression of microRNAs and genes that are implicated in reproduction, cholinergic signaling and stress responses (Smith et al., 2013; Taki et al., 2014). Kim and colleagues have also reported the effect of the isolated 1,2,3,4,6-penta-O-galloyl-b-D-glucose (PGG) from Curcuma longa $L$. on longevity using $C$. elegans as a model system (Ahn et al., 2013). Notably, they demonstrated that PGG reduced intracellular ROS (Reactive Oxygen Species) accumulation through elevated SOD (Superoxide Dismutase). C. elegans has been used for the discoveries of antimicrobial drugs (Ewbank and Zugasti, 2011; Squiban and Kurz, 2011), antifungal drugs (Anastassopoulou et al., 2011), and Alzheimer's disease drugs (Lublin and Link, 2013). Therefore, C. elegans provides a tremendous promise for the discovery of new disease or target-specific drugs, and studying the action mechanism of the newly identified or known drugs (or small-molecules) in a live animal.

\section{ACKNOWLEGEMENTS}

We thank the members of the Lee laboratory (Specifically 
Kobet et al. C. elegans as a Model System for the Identification of Drugs and Therapeutic Targets

Dr. Kwon), Dr. Ruiz-Echevarría, and Dr. Yang for helpful discussion. This work was supported in part by Research and Education Fund, Summer Biomedical Research Program for undergraduates, Oncology Internal Grant, and Brody Bridge Grant from Brody School of Medicine at East Carolina University to M.H.L. RTI University Collaboration Fund to M.H.L and X.P.

\section{REFERENCES}

Abel, E. V., Kim, E. J., Wu, J., Hynes, M., Bednar, F., Proctor, E., Wang, L., Dziubinski, M. L. and Simeone, D. M. (2014). The Notch pathway is important in maintaining the cancer stem cell population in pancreatic cancer. PLoS One 9, e91983.

Ahn, D., Cha, D. S., Lee, E. B., Kim, B. J., Lee, S. Y., Jeon, H., Ahn, M. S., Lim, H. W., Lee, H. Y. and Kim, D. K. (2013) The longevity properties of 1,2,3,4,6-Penta-O-Galloyl-beta-D-Glucose from Curcuma longa in Caenorhabditis elegans. Biomol. Ther. 21, 442-446.

Allenspach, E. J., Maillard, I., Aster, J. C. and Pear, W. S. (2002) Notch signaling in cancer. Cancer Biol. Ther. 1, 466-476.

Anastassopoulou, C. G., Fuchs, B. B. and Mylonakis, E. (2011) Caenorhabditis elegans-based model systems for antifungal drug discovery. Curr. Pharm. Des. 17, 1225-1233.

Artavanis-Tsakonas, S., Rand, M. D. and Lake, R. J. (1999) Notch signaling: cell fate control and signal integration in development. Science 284, 770-776

Austin, J. and Kimble, J. (1987) glp-1 is required in the germ line for regulation of the decision between mitosis and meiosis in $\mathrm{C}$. elegans. Cell 51, 589-599.

Avila, J. L. and Kissil, J. L. (2013) Notch signaling in pancreatic cancer: oncogene or tumor suppressor? Trends Mol. Med. 19, 320-327.

Bae, Y. K., Sung, J. Y., Kim, Y. N., Kim, S., Hong, K. M., Kim, H. T., Choi, M. S., Kwon, J. Y. and Shim, J. (2012) An in vivo C. elegans model system for screening EGFR-inhibiting anti-cancer drugs. PLoS One 7, e42441.

Bao, B., Wang, Z., Ali, S., Kong, D., Li, Y., Ahmad, A., Banerjee, S., Azmi, A. S., Miele, L. and Sarkar, F. H. (2011) Notch-1 induces epithelial-mesenchymal transition consistent with cancer stem cell phenotype in pancreatic cancer cells. Cancer Lett. 307, 26-36.

Beitel, G. J., Clark, S. G. and Horvitz, H. R. (1990) Caenorhabditis elegans ras gene let- 60 acts as a switch in the pathway of vulval induction. Nature 348, 503-509.

Benson, J. A., Cummings, E. E., O'Reilly, L. P., Lee, M. H. and Pak, S. C. (2014) A high-content assay for identifying small molecules that reprogram C. elegans germ cell fate. Methods 68, 529-535.

Berry, L. W., Westlund, B. and Schedl, T. (1997) Germ-line tumor formation caused by activation of glp-1, a Caenorhabditis elegans member of the Notch family of receptors. Development 124, 925936.

Berset, T., Hoier, E. F., Battu, G., Canevascini, S. and Hajnal, A. (2001) Notch inhibition of RAS signaling through MAP kinase phosphatase LIP-1 during C. elegans vulval development. Science 291, 1055-1058.

Birchmeier, W. (2011) Stem cells: Orphan receptors find a home. Nature 476, 287-288.

Blelloch, R., Anna-Arriola, S. S., Gao, D., Li, Y., Hodgkin, J. and Kimble, J. (1999) The gon-1 gene is required for gonadal morphogenesis in Caenorhabditis elegans. Dev. Biol. 216, 382-393.

Blelloch, R. and Kimble, J. (1999) Control of organ shape by a secreted metalloprotease in the nematode Caenorhabditis elegans. Nature 399, 586-590.

Byrd, D. T. and Kimble, J. (2009) Scratching the niche that controls Caenorhabditis elegans germline stem cells. Semin. Cell Dev. Biol. 20, 1107-1113.

Byrd, D. T., Knobel, K., Affeldt, K., Crittenden, S. L. and Kimble, J. (2014) A DTC niche plexus surrounds the germline stem cell pool in Caenorhabditis elegans. PloS One 9, e88372.

Cha, D. S., Datla, U. S., Hollis, S. E., Kimble, J. and Lee, M. H. (2012) The Ras-ERK MAPK regulatory network controls dedifferentiation in Caenorhabditis elegans germline. Biochim. Biophys. Acta 1823 1847-1855.

Chamorro, M. N., Schwartz, D. R., Vonica, A., Brivanlou, A. H., Cho, K. R. and Varmus, H. E. (2005) FGF-20 and DKK1 are transcriptional targets of beta-catenin and FGF-20 is implicated in cancer and development. EMBO J. 24, 73-84.

Chen, P. H., Chen, X., Lin, Z., Fang, D. and He, X. (2013) The structural basis of R-spondin recognition by LGR5 and RNF43. Genes Dev. 27, 1345-1350.

Datla, U. S., Scovill, N. C., Brokamp, A. J., Kim, E., Asch, A. S. and Lee, M. H. (2014) Role of PUF-8/PUF protein in stem cell control, sperm-oocyte decision and cell fate reprogramming. J. Cell. Physiol. 229, 1306-1311.

Duncia, J. V., Santella, J. B., 3rd, Higley, C. A., Pitts, W. J., Wityak, J., Frietze, W. E., Rankin, F. W., Sun, J. H., Earl, R. A., Tabaka, A C., Teleha, C. A., Blom, K. F., Favata, M. F., Manos, E. J., Daulerio, A. J., Stradley, D. A., Horiuchi, K., Copeland, R. A., Scherle, P. A., Trzaskos, J. M., Magolda, R. L., Trainor, G. L., Wexler, R. R., Hobbs, F. W. and Olson, R. E. (1998) MEK inhibitors: the chemistry and biological activity of U0126, its analogs, and cyclization products. Bioorg. Med. Chem. Lett. 8, 2839-2844.

Eckmann, C. R., Kraemer, B., Wickens, M. and Kimble, J. (2002) GLD3 , a bicaudal-C homolog that inhibits FBF to control germline sex determination in C. elegans. Dev. Cell 3, 697-710.

Eisenmann, D. M. (2005) Wnt signaling. WormBook 1-17.

Ewbank, J. J. and Zugasti, O. (2011) C. elegans: model host and tool for antimicrobial drug discovery. Dis. Model Mech. 4, 300-304.

Fan, X., Matsui, W., Khaki, L., Stearns, D., Chun, J., Li, Y. M. and Eberhart, C. G. (2006) Notch pathway inhibition depletes stem-like cells and blocks engraftment in embryonal brain tumors. Cancer Res. 66, 7445-7452.

Favata, M. F., Horiuchi, K. Y., Manos, E. J., Daulerio, A. J., Stradley, D. A., Feeser, W. S., Van Dyk, D. E., Pitts, W. J., Earl, R. A., Hobbs F., Copeland, R. A., Magolda, R. L., Scherle, P. A. and Trzaskos J. M. (1998) Identification of a novel inhibitor of mitogen-activated protein kinase kinase. J. Biol. Chem. 273, 18623-18632.

Feng, Z., Li, W., Ward, A., Piggott, B. J., Larkspur, E. R., Sternberg, P. W. and Xu, X. Z. (2006) A C. elegans model of nicotine-dependent behavior: regulation by TRP-family channels. Cell 127, 621-633.

Ferrando, A. A. (2009) The role of NOTCH1 signaling in T-ALL. Hematology Am. Soc. Hematol. Educ. Program, 353-361.

Galluzzo, P. and Bocchetta, M. (2011) Notch signaling in lung cancer. Expert Rev. Anticancer Ther. 11, 533-540.

Greenwald, I. (2005) LIN-12/Notch signaling in C. elegans. WormBook, 1-16.

Hajnal, A. and Berset, T. (2002) The C. elegans MAPK phosphatase LIP-1 is required for the $\mathrm{G}(2) / \mathrm{M}$ meiotic arrest of developing oocytes. EMBO J. 21, 4317-4326.

Hara, M. and Han, M. (1995) Ras farnesyltransferase inhibitors suppress the phenotype resulting from an activated ras mutation in Caenorhabditis elegans. Proc. Natl. Acad. Sci. U.S.A. 92, 33333337.

He, T. C., Sparks, A. B., Rago, C., Hermeking, H., Zawel, L., da Costa, L. T., Morin, P. J., Vogelstein, B. and Kinzler, K. W. (1998) Identification of C-MYC as a target of the APC pathway. Science 281, 1509-1512.

Henderson, S. T., Gao, D., Lambie, E. J. and Kimble, J. (1994) lag-2 may encode a signaling ligand for the GLP-1 and LIN-12 receptors of C. elegans. Development 120, 2913-2924.

Holland, J. D., Klaus, A., Garratt, A. N. and Birchmeier, W. (2013) Wnt signaling in stem and cancer stem cells. Curr. Opin. Cell Biol. 25, 254-264.

Hughes, D. P. (2009) How the NOTCH pathway contributes to the ability of osteosarcoma cells to metastasize. Cancer Treat. Res. 152 479-496

James, R. G., Conrad, W. H. and Moon, R. T. (2008) Beta-cateninindependent Wnt pathways: signals, core proteins, and effectors. Methods Mol. Biol. 468, 131-144.

Katoh, M. (2008) WNT signaling in stem cell biology and regenerative medicine. Curr. Drug Targets 9, 565-570.

Kershner, A. M., Shin, H., Hansen, T. J. and Kimble, J. (2014) Discovery of two GLP-1/Notch target genes that account for the role of 
GLP-1/Notch signaling in stem cell maintenance. Proc. Natl. Acad. Sci. U.S.A. 111, 3739-3744.

Kidd, A. R., 3rd, Miskowski, J. A., Siegfried, K. R., Sawa, H. and Kimble, J. (2005) A beta-catenin identified by functional rather than sequence criteria and its role in Wnt/MAPK signaling. Cell 121, 761-772.

Kimble, J. and Crittenden, S. L. (2005) Germline proliferation and its control. WormBook, 1-14.

Kimble, J. and Crittenden, S. L. (2007) Controls of germline stem cells, entry into meiosis, and the sperm/oocyte decision in Caenorhabditis elegans. Annu. Rev. Cell Dev. Biol. 23, 405-433.

Lackner, M. R. and Kim, S. K. (1998) Genetic analysis of the Caenorhabditis elegans MAP kinase gene mpk-1. Genetics 150, 103117.

Lam, N., Chesney, M. A. and Kimble, J. (2006) Wnt signaling and CEH-22/tinman/Nkx2.5 specify a stem cell niche in C. elegans. Curr. Biol. 16, 287-295.

Lamont, L. B., Crittenden, S. L., Bernstein, D., Wickens, M. and Kimble, J. (2004) FBF-1 and FBF-2 regulate the size of the mitotic region in the C. elegans germline. Dev. Cell 7, 697-707.

Lee, M. H., Cha, D. S., Mamillapalli, S. S., Kwon, Y. C. and Koo, H. S. (2014) Transgene-mediated co-suppression of DNA topoisomerase-1 gene in Caenorhabditis elegans. Int. Biochem. Mol. Biol. 5, 11-20.

Lee, M. H., Hook, B., Lamont, L. B., Wickens, M. and Kimble, J. (2006) LIP-1 phosphatase controls the extent of germline proliferation in Caenorhabditis elegans. EMBO J. 25, 88-96.

Lee, M. H., Hook, B., Pan, G., Kershner, A. M., Merritt, C., Seydoux, G., Thomson, J. A., Wickens, M. and Kimble, J. (2007a) Conserved regulation of MAP kinase expression by PUF RNA-binding proteins. PLoS Genet. 3, e233.

Lee, M. H., Ohmachi, M., Arur, S., Nayak, S., Francis, R., Church, D., Lambie, E. and Schedl, T. (2007b) Multiple functions and dynamic activation of MPK-1 extracellular signal-regulated kinase signaling in Caenorhabditis elegans germline development. Genetics 177, 2039-2062.

Lino, M. M., Merlo, A. and Boulay, J. L. (2010) Notch signaling in glioblastoma: a developmental drug target? BMC Med. 8, 72.

Liu, J., Sato, C., Cerletti, M. and Wagers, A. (2010) Notch signaling in the regulation of stem cell self-renewal and differentiation. Curr. Top. Dev. Biol. 92, 367-409.

Lomenick, B., Hao, R., Jonai, N., Chin, R. M., Aghajan, M., Warburton, S., Wang, J., Wu, R. P., Gomez, F., Loo, J. A., Wohlschlegel, J. A., Vondriska, T. M., Pelletier, J., Herschman, H. R., Clardy, J., Clarke, C. F. and Huang, J. (2009) Target identification using drug affinity responsive target stability (DARTS). Proc. Natl. Acad. Sci. U.S.A. 106, 21984-21989.

Lomenick, B., Jung, G., Wohlschlegel, J. A. and Huang, J. (2011) Target identification using drug affinity responsive target stability (DARTS). Curr. Protoc. Chem. Biol. 3, 163-180.

Lopez, A. L., 3rd, Chen, J., Joo, H. J., Drake, M., Shidate, M., Kseib, C. and Arur, S. (2013) DAF-2 and ERK couple nutrient availability to meiotic progression during Caenorhabditis elegans oogenesis. Dev. Cell 27, 227-240.

Lublin, A. L. and Link, C. D. (2013) Alzheimer's disease drug discovery: in vivo screening using Caenorhabditis elegans as a model for beta-amyloid peptide-induced toxicity. Drug Discov. Today Technol. 10, e115-119.

Maine, E. M. and Kimble, J. (1989) Identification of genes that interact with glp-1, a gene required for inductive cell interactions in Caenorhabditis elegans. Development 106, 133-143.

Marshall, M. (1995) Interactions between Ras and Raf: key regulatory proteins in cellular transformation. Mol. Reprod. Dev. 42, 493-499.

Miyamoto, S. and Rosenberg, D. W. (2011) Role of Notch signaling in colon homeostasis and carcinogenesis. Cancer Sci. 102, 19381942.

Moon, B. S., Jeong, W. J., Park, J., Kim, T. I., Min do, S. and Choi, K. Y. (2014) Role of oncogenic K-Ras in cancer stem cell activation by aberrant Wnt/beta-catenin signaling. J. Natl. Cancer Inst. 106, djt373.

Morgan, C. T., Lee, M. H. and Kimble, J. (2010) Chemical reprogramming of Caenorhabditis elegans germ cell fate. Nat. Chem. Biol.
6, 102-104.

Nadarajan, S., Govindan, J. A., McGovern, M., Hubbard, E. J. and Greenstein, D. (2009) MSP and GLP-1/Notch signaling coordinately regulate actomyosin-dependent cytoplasmic streaming and oocyte growth in C. elegans. Development 136, 2223-2234.

Nusse, R., Fuerer, C., Ching, W., Harnish, K., Logan, C., Zeng, A., ten Berge, D. and Kalani, Y. (2008) Wnt signaling and stem cell control. Cold Spring Harb. Symp. Quant. Biol. 73, 59-66.

Nykamp, K., Lee, M. H. and Kimble, J. (2008) C. elegans La-related protein, LARP-1, localizes to germline $P$ bodies and attenuates Ras-MAPK signaling during oogenesis. RNA 14, 1378-1389.

O'Reilly, L. P., Luke, C. J., Perlmutter, D. H., Silverman, G. A. and Pak, S. C. (2014) C. elegans in high-throughput drug discovery. Adv. Drug Deliv. Rev. 69-70, 247-253.

Okabe, H., Lee, S. H., Phuchareon, J., Albertson, D. G., McCormick, F. and Tetsu, O. (2006) A critical role for FBXW8 and MAPK in cyclin D1 degradation and cancer cell proliferation. PLoS One 1, e128.

Pennica, D., Swanson, T. A., Welsh, J. W., Roy, M. A., Lawrence, D. A., Lee, J., Brush, J., Taneyhill, L. A., Deuel, B., Lew, M., Watanabe, C., Cohen, R. L., Melhem, M. F., Finley, G. G., Quirke, P., Goddard A. D., Hillan, K. J., Gurney, A. L., Botstein, D. and Levine, A. J. (1998) WISP genes are members of the connective tissue growth factor family that are up-regulated in wnt-1-transformed cells and aberrantly expressed in human colon tumors. Proc. Natl. Acad. Sci. U.S.A. 95, 14717-14722.

Pepper, A. S., Killian, D. J. and Hubbard, E. J. (2003a) Genetic analysis of Caenorhabditis elegans glp-1 mutants suggests receptor interaction or competition. Genetics 163, 115-132.

Pepper, A. S., Lo, T. W., Killian, D. J., Hall, D. H. and Hubbard, E. J. (2003b) The establishment of Caenorhabditis elegans germline pattern is controlled by overlapping proximal and distal somatic gonad signals. Dev. Biol. 259, 336-350.

Petcherski, A. G. and Kimble, J. (2000) LAG-3 is a putative transcriptional activator in the C. elegans Notch pathway. Nature 405, 364368.

Phillips, B. T., Kidd, A. R., 3rd, King, R., Hardin, J. and Kimble, J. (2007) Reciprocal asymmetry of SYS-1/beta-catenin and POP-1/ TCF controls asymmetric divisions in Caenorhabditis elegans. Proc. Natl. Acad. Sci. U.S.A. 104, 3231-3236.

Reedijk, M. (2012) Notch signaling and breast cancer. Adv. Exp. Med. Biol. 727, 241-257.

Reya, T. and Clevers, H. (2005) Wnt signalling in stem cells and cancer. Nature 434, 843-850.

Ristorcelli, E. and Lombardo, D. (2010) Targeting Notch signaling in pancreatic cancer. Expert Opin. Ther. Targets 14, 541-552.

Saxena, N., Lahiri, S. S., Hambarde, S. and Tripathi, R. P. (2008) RAS: target for cancer therapy. Cancer Invest. 26, 948-955.

Schouest, K. R., Kurasawa, Y., Furuta, T., Hisamoto, N., Matsumoto, K. and Schumacher, J. M. (2009) The germinal center kinase GCK1 is a negative regulator of MAP kinase activation and apoptosis in the C. elegans germline. PLoS One 4, e7450.

Schulze, W. X., Deng, L. and Mann, M. (2005) Phosphotyrosine interactome of the ErbB-receptor kinase family. Mol. Syst. Biol. 1, 20050008.

Sellings, L., Pereira, S., Qian, C., Dixon-McDougall, T., Nowak, C., Zhao, B., Tyndale, R. F. and van der Kooy, D. (2013) Nicotine-motivated behavior in Caenorhabditis elegans requires the nicotinic acetylcholine receptor subunits acr-5 and acr-15. Eur. J. Neurosci. 37, 743-756.

Siegfried, K. R. and Kimble, J. (2002) POP-1 controls axis formation during early gonadogenesis in C. elegans. Development 129, 443453.

Smith, M. A., Jr., Zhang, Y., Polli, J. R., Wu, H., Zhang, B., Xiao, P., Farwell, M. A. and Pan, X. (2013) Impacts of chronic low-level nicotine exposure on Caenorhabditis elegans reproduction: identification of novel gene targets. Reprod. Toxicol. 40, 69-75.

Squiban, B. and Kurz, C. L. (2011) C. elegans: an all in one model for antimicrobial drug discovery. Curr. Drug Targets 12, 967-977.

Sun, W., Gaykalova, D. A., Ochs, M. F., Mambo, E., Arnaoutakis, D., Liu, Y., Loyo, M., Agrawal, N., Howard, J., Li, R., Ahn, S., Fertig, E., Sidransky, D., Houghton, J., Buddavarapu, K., Sanford, T., Choudhary, A., Darden, W., Adai, A., Latham, G., Bishop, J., Sharma, R., 
Kobet et al. C. elegans as a Model System for the Identification of Drugs and Therapeutic Targets

Westra, W. H., Hennessey, P., Chung, C. H. and Califano, J. A. (2014) Activation of the NOTCH pathway in head and neck cancer. Cancer Res. 74, 1091-1104.

Sundaram, M. V. (2006) RTK/Ras/MAPK signaling. WormBook, 1-19.

Taki, F. A., Pan, X. and Zhang, B. (2014) Chronic nicotine exposure systemically alters microRNA expression profiles during postembryonic stages in Caenorhabditis elegans. J. Cell. Physiol. 229, 79-89.

Tamura, Y., Simizu, S. and Osada, H. (2004) The phosphorylation status and anti-apoptotic activity of $\mathrm{Bcl}-2$ are regulated by ERK and protein phosphatase $2 \mathrm{~A}$ on the mitochondria. FEBS Lett. 569, 249255

Tetsu, O. and McCormick, F. (1999) Beta-catenin regulates expression of cyclin D1 in colon carcinoma cells. Nature 398, 422-426.

Tilmann, C. and Kimble, J. (2005) Cyclin D regulation of a sexually dimorphic asymmetric cell division. Dev. Cell 9, 489-499.

Towatari, M., Ciro, M., Ottolenghi, S., Tsuzuki, S. and Enver, T. (2004) Involvement of mitogen-activated protein kinase in the cytokineregulated phosphorylation of transcription factor GATA-1. Hematol. J. 5, 262-272.

Vaid, S., Ariz, M., Chaturbedi, A., Kumar, G. A. and Subramaniam, K.
(2013) PUF-8 negatively regulates RAS/MAPK signalling to promote differentiation of $C$. elegans germ cells. Development 140 , 1645-1654.

Visvader, J. E. and Lindeman, G. J. (2012) Cancer stem cells: current status and evolving complexities. Cell stem cell 10, 717-728.

Wang, D., Huang, B., Zhang, S., Yu, X., Wu, W. and Wang, X. (2013) Structural basis for R-spondin recognition by LGR4/5/6 receptors. Genes Dev. 27, 1339-1344.

Wend, P., Holland, J. D., Ziebold, U. and Birchmeier, W. (2010) Wnt signaling in stem and cancer stem cells. Semin. Cell Dev. Biol. 21 855-863.

Whelan, J. T., Hollis, S. E., Cha, D. S., Asch, A. S. and Lee, M. H. (2012) Post-transcriptional regulation of the Ras-ERK/MAPK signaling pathway. J. Cell. Physiol. 227, 1235-1241.

Yoo, A. S., Bais, C. and Greenwald, I. (2004) Crosstalk between the EGFR and LIN-12/Notch pathways in C. elegans vulval development. Science 303, 663-666.

Zhao, Y., Bjorbaek, C. and Moller, D. E. (1996) Regulation and interaction of pp90(rsk) isoforms with mitogen-activated protein kinases. J. Biol. Chem. 271, 29773-29779. 